\title{
Effects of seasonal air temperature variation on airflow and surrounding rock temperature of mines
}

\author{
Xin $\mathrm{Yi}^{1,3} \cdot$ Lifeng $\operatorname{Ren}^{2,3}\left(\mathrm{Li}^{\mathrm{C}} \mathrm{Ma}^{1,3} \cdot\right.$ Gaoming $\mathrm{Wei}^{1,3} \cdot$ Wencong $\mathrm{Yu}^{1,3} \cdot$ \\ Jun Deng ${ }^{1,3} \cdot$ Chimin Shu ${ }^{4}$
}

Received: 9 April 2019/Revised: 17 July 2019/Accepted: 13 August 2019/Published online: 26 August 2019

(C) The Author(s) 2019

\begin{abstract}
In underground mines, high air temperatures in the summer months lead to an increase in inlet airflow temperatures. This leads to seasonal thermal pollution in the mines. This paper examines the dynamics and effects of seasonal variation in surface air temperatures and surrounding rock temperatures in deep coal mines. It also examines temperature variations in the main ventilation circuit, working face, and surrounding rock. The study results revealed that airflow temperatures were significantly affected by seasonal air temperature variations. The greater the distance was between the inlet and the wellhead of the ventilation shaft, the less the effect was on temperature. Moreover, slight temperature variations $\left(1.0-3.0^{\circ} \mathrm{C}\right)$ were observed between various points on the return route during the summer months. Airflow temperatures along the airflow inlet to the return route of the working face first decreased, but then increased. The temperature field of the surrounding rock increased gradually with increased distance between the mine roadway and inlet, with recorded rock temperatures as high as $40.53{ }^{\circ} \mathrm{C}$. The radius of the heat-adjusting layer was between 28 and $33 \mathrm{~m}$.
\end{abstract}

Keywords Seasonal variation $\cdot$ Fiber optic temperature measurement $\cdot$ Real-time monitoring $\cdot$ Deep coal mine $\cdot$ Thermal pollution $\cdot$ Heat-adjusting layer

Lifeng Ren

lifengrr@126.com

Li Ma

mal@xust.edu.cn

1 School of Safety Science and Engineering, Xi' an University of Science and Technology, Xi' an 710054, People's Republic of China

2 Post-doctoral Research Center of Mining Engineering, Xi' an University of Science and Technology, 58, Yanta Mid. Rd., Xi'an 710054, Shaanxi, People's Republic of China

3 Shaanxi Key Laboratory of Prevention and Control of Coal Fire, Xi'an 710054, People's Republic of China

4 Graduate School of Engineering Science and Technology, National Yunlin University of Science and Technology, 123, University Rd., Sec. 3, Douliou 64002, Yunlin, Taiwan, ROC

\section{Introduction}

There are many large underground mines, defined as such on the basis of production, horizontal extent, and depth. However, deep mining has led to an increase in the thermal hazard, which affects the production of conventional mine, poses potential risks to the health and wellbeing of miners, and threatens mining efficiency (He and Guo 2013; Yang et al. 2011). In China, there are 200 coal mines at depths $>800 \mathrm{~m}$, and 47 of these are at depths $>1000 \mathrm{~m}$ (Xie et al. 2012). As mining depth increases, the severity of the effects of seasonal thermal pollution increases. Other types of thermal pollution include those caused by heat dissipation from surrounding rocks and electrical equipment, as well from mineral oxidation ( $\mathrm{He}$ et al. 2010; $\mathrm{Su}$ et al. 2009). Studies have been conducted on the origins of mine thermal pollution and methods for its detection and prevention. Such studies have helped improve the production environment, decrease accident rates, and enhance productivity (Chen et al. 2016). 
An extensive body of literature has documented studies on thermal pollution in mines. Heerden (1951) analyzed field temperature distributions of underground rock circles in ideal conditions, and more recently Castillo et al. (2003) focused on high-temperature problems in platinum mines in North Africa and analyzed a cooling system in detail. Pherson (2012) and Yakovenko and Averin (1984) calculated the heat transfer coefficient of roadway airflow of mines. Chu (2015) quantitatively described the thermal parameters of underground air and related thermal characteristics. Xie (2012) proposed that the heat diffusion of surrounding rock was the primary source of thermal pollution in fully mechanized mining faces. Danko and Bahrami (2008) and Ngô et al. (2017) investigated the variation in temperature fields and heat transformation patterns of rocks surrounding mine shafts at different temperatures and humidity levels. Lowndes et al. (2004a, b) and Guo et al. (2017) established a geothermal recycling system for mines, which effectively recovered waste heat and increased energy use by $20 \%$. Lowndes et al. 2004a, b and Hargreaves and Lowndes (2007) combined theoretical and simulation methods to explore the relationship between mine ventilation and climatic conditions at different sites at the working face of mines. Onder et al. (2006) and Kamyar et al. (2016) studied the connections between local ventilation and heat transformation. The results indicated that cooling air could effectively reduce the temperature in mining areas. Nie et al. (2018) analyzed the factors causing downhole thermal pollution at high temperatures, resulting in optimization and rebuilding of the mine ventilation system, and establishment of a cooling system. Apel et al. (2014) identified hysteretic behavior of floor rocks that attenuated heat dissipation between surrounding rock and the air. Zhang et al. (2006) and Wang et al. (2018) used heat transfer theory to present a three-dimensional nonlinear relationship between heat convection of the surrounding rock and air. In sum, numerous studies have been conducted to characterize and alleviate mine thermal pollution.

However, very few studies have analyzed the effect of seasonal surface temperature variation on mine thermal pollution. Thermal pollution in mines varies regularly due to seasonal changes in surface air temperatures. Working areas of mines experience thermal pollution when airflow temperatures exceed specified safety values, particularly in the summer. Airflow temperature is a critical parameter for assessing the degree of thermal pollution. Seasonal variation in surface air temperature has a considerable effect on the temperature field of surrounding rocks in the mine roadway, and also on airflow temperature. Therefore, studying the influence of seasonal variations in ground air temperature on airflow and surrounding rock temperatures will help to evaluate, prevent, and control thermal pollution in underground mines.

The present study combined manually measured temperatures and temperature measurements obtained from fiber optics in the Juye mining area (Shandong Province, China). Airflow temperature variations over a period of 1 year were analyzed, with the goals of:

(1) Understanding how the main ventilation route of the mine is influenced by seasonal variations in airflow temperatures.

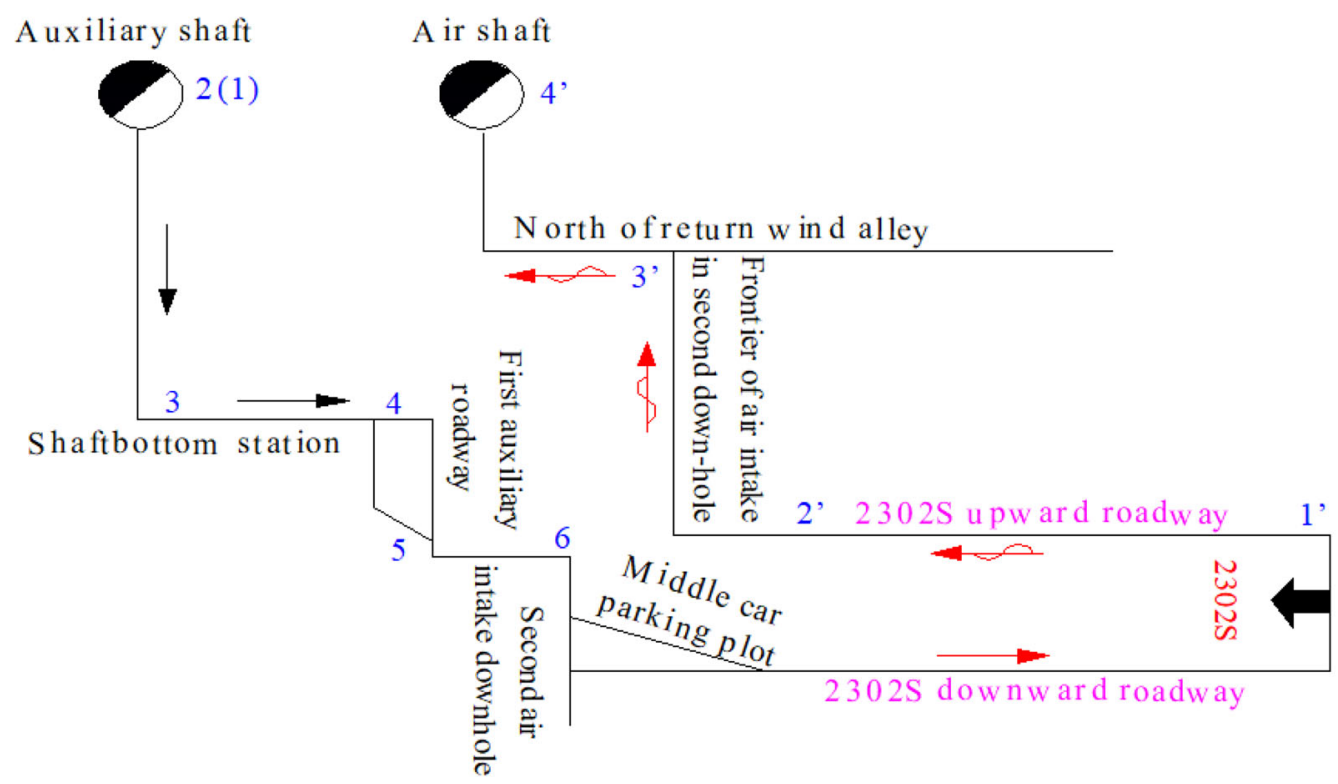

Fig. 1 Arrangement of measuring points (MPs; shown by blue numerals) on the main ventilation routes 

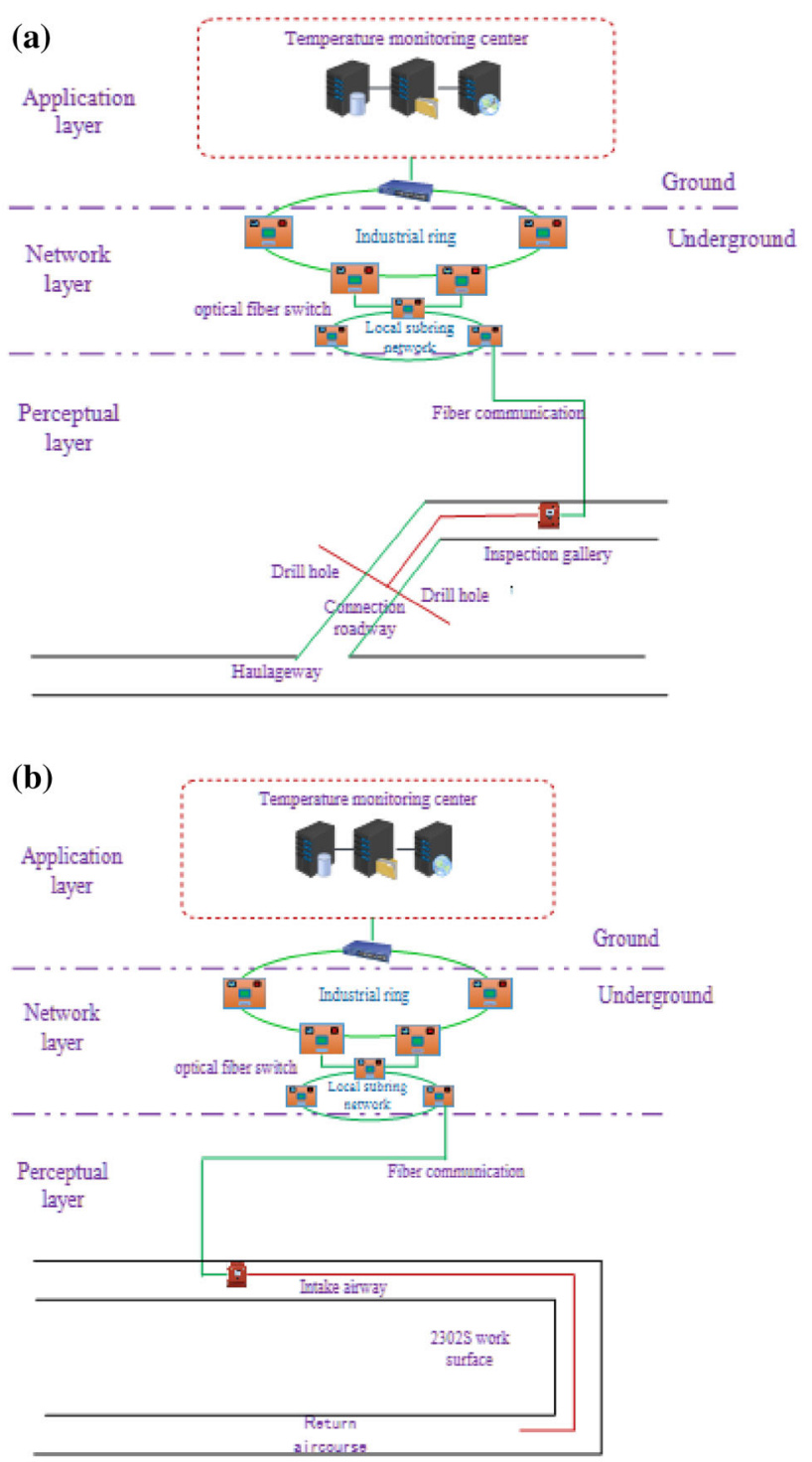

Fig. 2 Fiber optic temperature measurement system showing a rock temperature field measurement and $\mathbf{b}$ measurement of airflow temperature at the working face

(2) Evaluating the development of thermal pollution at the coal mining face in real time using a fiber optic temperature measurement system.

(3) Determining the radius of the heat-adjusting layer of surrounding rock based on a fiber optic temperature measurement system.

\section{Mine conditions and methodology}

\subsection{Overview of the Juye mine}

The mine selected for the current study is located in the south-central area of the Juye Coal Field in the Shandong Province of China. The designed annual production capacity is approximately 6 million tons, with an annual average temperature of $13.9{ }^{\circ} \mathrm{C}$ and a monthly average maximum temperature of $32.4{ }^{\circ} \mathrm{C}$ (July 1998, in which the highest temperature was recorded). The monthly average minimum temperature is $-5.2{ }^{\circ} \mathrm{C}$ (January 1998) and the hottest month is July.

\subsubsection{Mine ventilation}

The mine in the study is an underground mine that uses negative pressure ventilation. The mine contains five shafts: the main shafts (two shafts), an auxiliary shaft, and the southern return air shaft, which is located at the main surface plant of the mine. The northern return air shaft serves the northern area of the mining field. The auxiliary shaft is the main air inlet shaft, and the two wind shafts are dedicated to return airflow for the entire mine. Air intake for the entire mine is approximately $20,000 \mathrm{~m}^{3} / \mathrm{min}$, and the ventilation volume of the 2302 working face is $2000 \mathrm{~m}^{3} / \mathrm{min}$. The length of the working face is $270 \mathrm{~m}$ and the slope length of the working face is $1521 \mathrm{~m}$.

\subsubsection{Geothermal conditions}

A total of six recoverable and partially recoverable coal seams occur in the mine, with an average total thickness of $9.62 \mathrm{~m}$. The coal seams are numbered 3, 4, 15, 16, 17, and 18. The primary coal seam, Coal Seam 3 , has an average thickness of $6.88 \mathrm{~m}$ and contains $72 \%$ of the total thickness of recoverable coal in the mine. The depth of mining is $-810 \mathrm{~m}$ and the constant temperature zone is $50 \mathrm{~m}$ in depth with a temperature of $18.9^{\circ} \mathrm{C}$. The average geothermal gradient of the coal-bearing strata is $2.88{ }^{\circ} \mathrm{C} /$ $100 \mathrm{~m}$ while the average geothermal gradient of the noncoal strata is $2.52{ }^{\circ} \mathrm{C} / 100 \mathrm{~m}$. The average surface temperature gradient of the coal strata is $3.23{ }^{\circ} \mathrm{C} / 100 \mathrm{~m}$ and the average floor temperature of Coal Seam 3 is $41.38{ }^{\circ} \mathrm{C}$.

\subsection{Variation in airflow temperature in the main ventilation circuit}

Surface and air temperature were measured for a year, using six measuring points (MPs). Data were recorded from the auxiliary shaft of the airflow inlet (MP1 and MP2) and the bottom of the auxiliary shaft (MP3). MP4 was set 


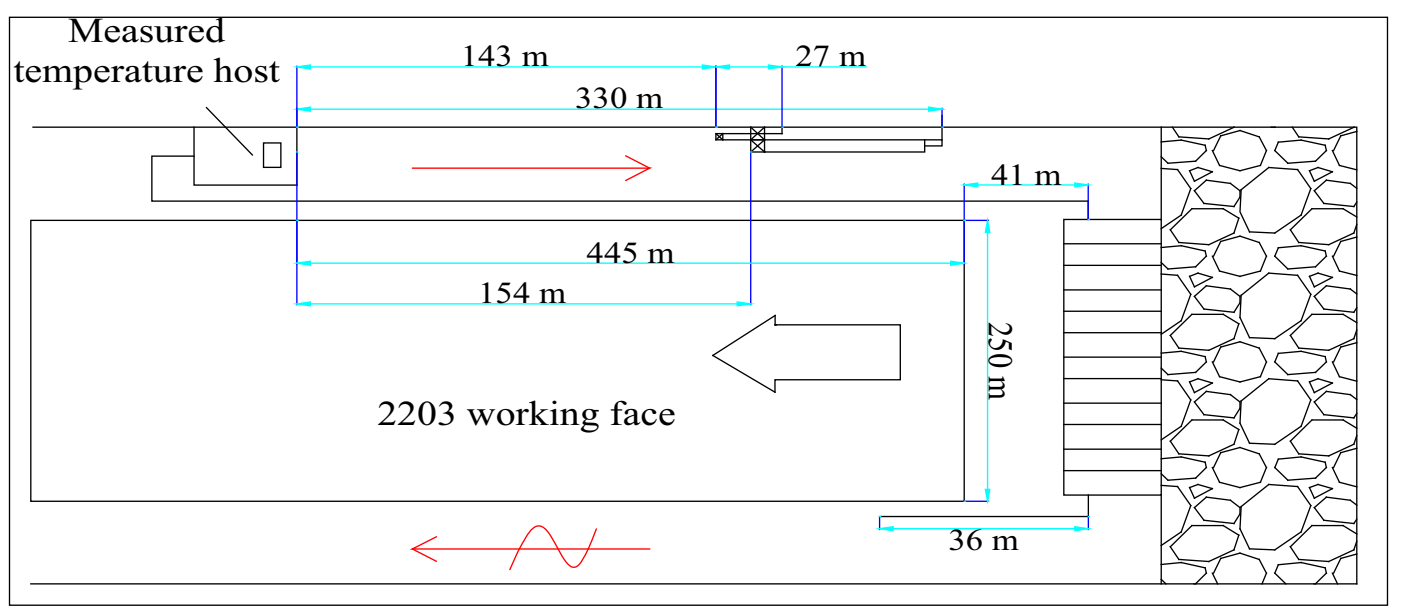

Fig. 3 Arrangement of the fiber optic temperature measurement system on the working face

Table 1 Measurement parameters of the drilling holes

\begin{tabular}{llcccc}
\hline Drilling number & Depth $(\mathrm{m})$ & Horizontal angle $\left(^{\circ}\right)$ & Vertical angle $\left(^{\circ}\right)$ & Time $($ day $)$ & Fiber length $(\mathrm{m})$ \\
\hline 1 & 50 & 6 & 0 & 4 & 100 \\
2 & 50 & 70 & 90 & 5 & 170 \\
3 & 50 & 55 & 60 & 6 & 128 \\
\hline
\end{tabular}

in the shaft station, MP5 was set in the airflow of the main and auxiliary shaft, and MP6 was set in the entrance of the working face. MP1' was set in the return airflow side of the working face, MP2' was set at the exit of the return airflow, $\mathrm{MP}^{\prime}$ was set at the bottom of the return shaft, and MP4' was set at the return air shaft outlet. A diagrammatic representation of all the MPs along the main ventilation routes is displayed in Fig. 1.

\subsection{Methods of testing air temperature at the working face and surrounding rock temperature}

Figure 2 displays the fiber optic system used to measure the airflow temperature and surrounding rock temperature. Some challenges were faced in deploying the system, such as the need for numerous thermistors, high-precision linearity and continuity of measurements, and difficulties in confirming measuring points and conducting maintenance. To measure the temperature range of the surrounding rock accurately, the roadway was used to maintain stable ventilation for a certain period. In this study, the use of a connection roadway was adopted. As displayed in Fig. 2a, two primary intake airflows converge to form a monitoring site for the surrounding rock temperature field in the roadway. The locations of the airflow temperature MPs on the working face are displayed in Fig. 2b. The layout of the optical fiber was "U" type, in which a fiber optic temperature detection cable was fixed on the front bracket of the working face, as shown in Fig. 3. The cable is exposed to the working face airflow via the intake and the front portion of the support. A margin of $0.8 \mathrm{~m}$ was maintained to ensure accurate measurements.

The roadway in Fig. $2 \mathrm{a}$ has a semicircular arch shape (width $6.0 \mathrm{~m}$ and height $4.0 \mathrm{~m}$ ), and the airflow supply of the crossheading was set to $800 \mathrm{~m}^{3} / \mathrm{min}$, which has been maintained for 6 years. Three drill holes were advanced in the same plane, with horizontal angles of $6^{\circ}, 70^{\circ}$ and $55^{\circ}$, as shown by the roadway positions in Fig. 2a. The MP of the surrounding rock temperature field was selected to be $50 \mathrm{~m}$ away from the inspection channel of the three drill holes. The depth of the temperature measuring hole was $50 \mathrm{~m}$, and the temperature-sensitive fiber was installed in the drill hole. After the measured temperature reached a stable status, a measured temperature curve was plotted to show the variation in surrounding rock temperature relative to drilling depth. The fibers were fastened in the holes, and each hole was sealed with cement $0.2 \mathrm{~m}$ in thickness. The parameters of the holes are listed in Table 1.

\subsection{Relational analysis}

Relational analysis is a systematic method that can quantitatively compare and describe subjects in which causes and effects contain multiple complex unknowns. The core aim of relational analysis in this study is to determine 


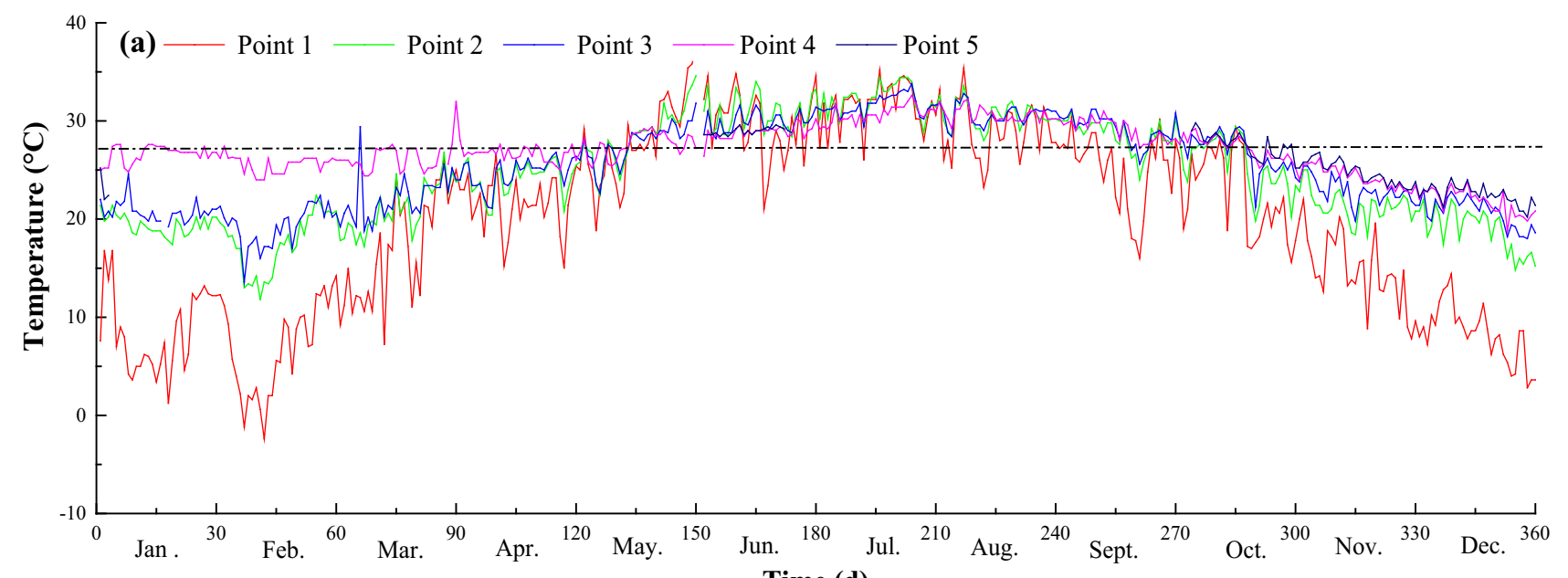

Time (d)

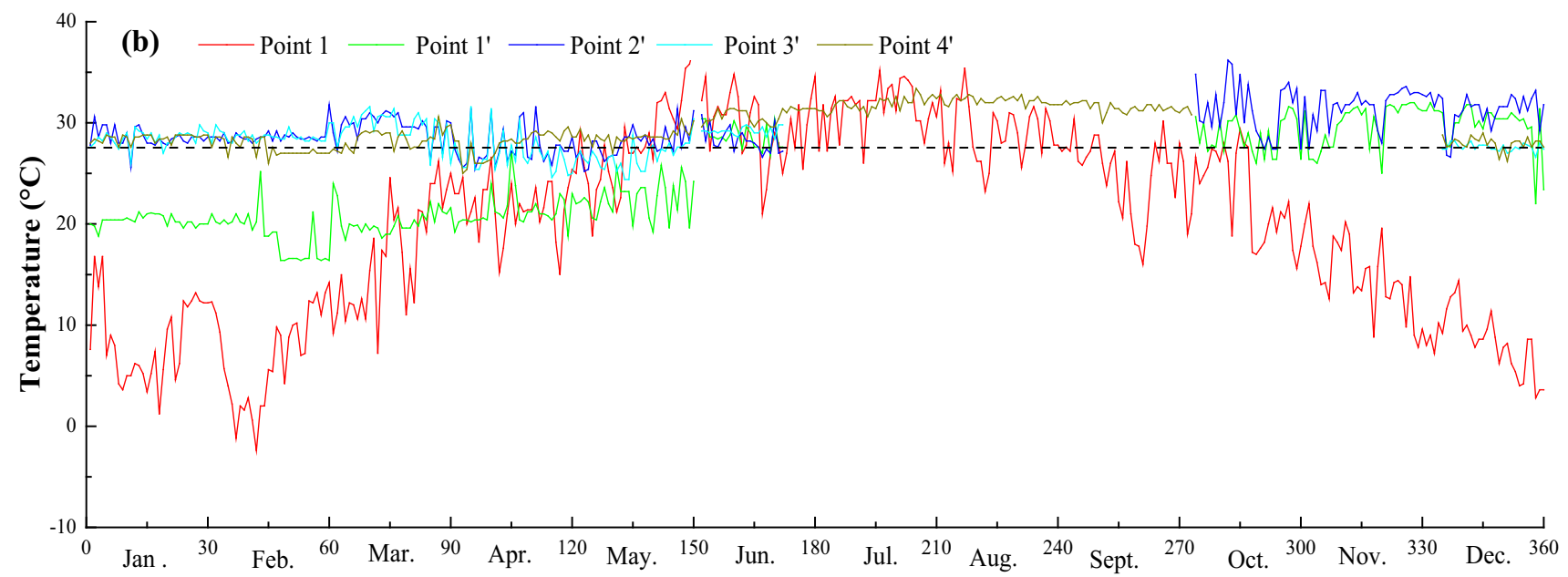

Time (d)

Fig. 4 Temperature changes in the $\mathbf{a}$ intake ventilation routes and the $\mathbf{b}$ return ventilation routes

Table 2 Correlations between surface air temperatures and temperatures recorded at underground MPs

\begin{tabular}{lll}
\hline Location & Correlation coefficient & Correlation \\
\hline $1-2$ & 0.950 & Correlated \\
$1-4$ & 0.923 & Correlated \\
$1-5$ & 0.755 & Correlated \\
$1-7$ & 0.551 & Uncorrelated \\
$1-1^{\prime}$ & 0.409 & Uncorrelated \\
$1-2^{\prime}$ & 0.373 & Uncorrelated \\
$1-3$ & 0.294 & Uncorrelated \\
$1-3^{\prime}$ & 0.647 & Correlated \\
\hline
\end{tabular}

whether the influencing factors and research objects are closely linked, and how much these factors influence the outcome. The analysis is based on the similarity degree of the geometric shape of the sequence curves obtained. Simultaneously, the closeness degree between the research object and the influencing factors is described using the relational degree (Raghavendra and Vinod 2009). The correlation coefficient $(P)$ of the Pearson theory reflects the degree of linear correlation between two data aggregates. The equation for such is shown below (Deng et al. 2014):

$P=\frac{n\left[\sum X Y-\left(\sum X\right)\left(\sum Y\right)\right]}{\sqrt{\left[n \sum X^{2}-\left(\sum X\right)^{2}\right]\left[n \sum Y^{2}-\left(\sum Y\right)^{2}\right]}}$

The correlation coefficient $P$ is a dimensionless index ranging from -1.0 to 1.0 , and it has been proven as an effective method for evaluating the degree of linear correlation between two data aggregates. 

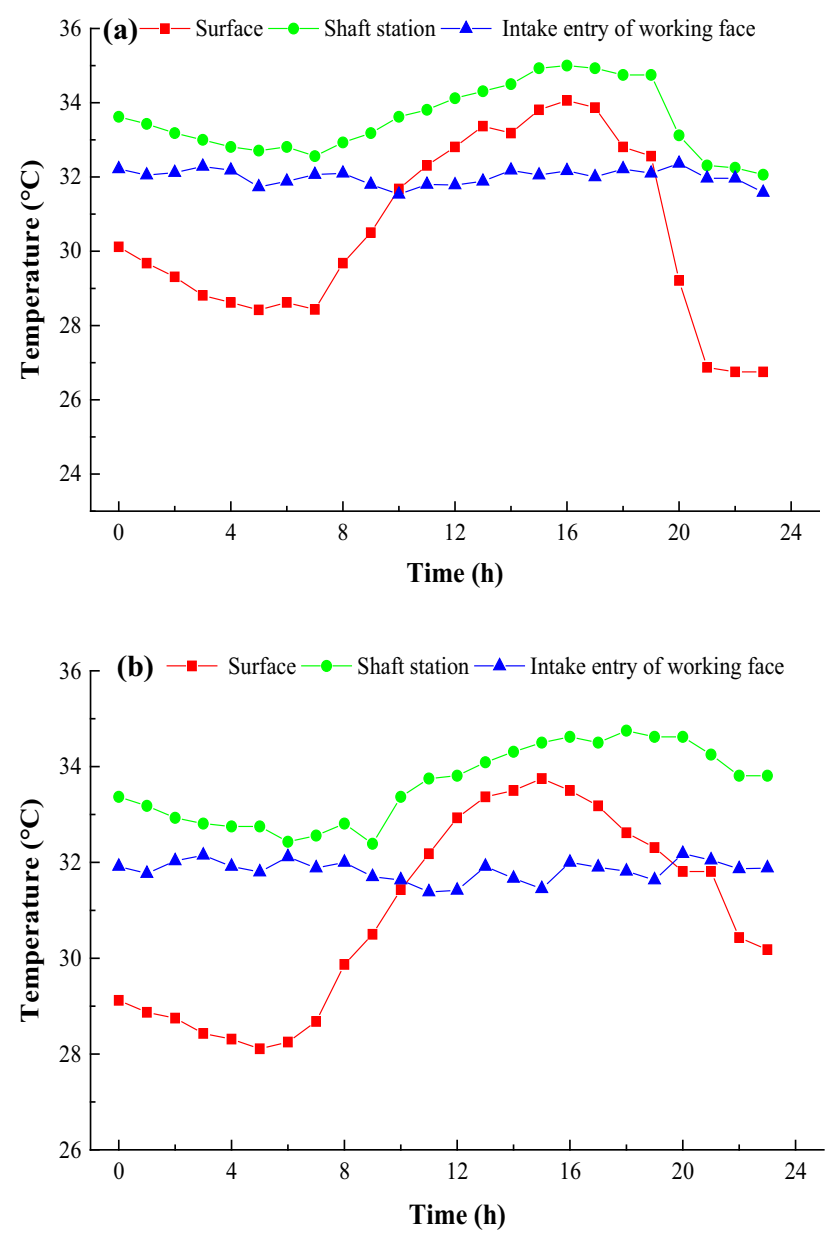

Fig. 5 Correlation between surface and underground temperatures recorded on a 02 August 2013 and b 03 August 2013

\section{Results and discussion}

\subsection{Effect of surface air temperature variation on underground airflow temperature}

Variations in airflow temperature at different MPs on the primary ventilation route were obtained by continuous monitoring for one year, as presented in Fig. 4.

The variation in airflow temperature at each MP along the air intake route is related to the surface air temperature. The similarity between curves decreases as the ventilation distance increases, as shown in Fig. 4a. The exchange of heat and humidity between the air and surrounding rock also appears to have taken some time. Therefore, it can be concluded that surface air temperature strongly influences air temperature in the intake route. Furthermore, this effect gradually decreases as the distance between the MP and the ventilation shaft wellhead increases. As airflow distance in the roadway increases, the degree of heat exchange between the surrounding rock and the air increases. Also, the temperature difference between the air and surrounding rock gradually decreases. The heat and humidity exchange between the air and surrounding rock abates the temperature difference between the air and surrounding rock before the airflow reaches the inlet roadway of the working face.

This substantially weakens the influence of the surface air temperature on air temperatures in the mine. The variation in airflow temperature at the MP on the return air route is small, and the influence of surface air temperature on airflow temperature changes is limited, as shown in Fig. 4b. When airflow crosses a working face, airflow temperatures increase significantly. This is related to, amongst other factors, heat dissipation from electrical equipment, coal cutting, and the goaf. The return airflow temperature increases and stabilizes within a small temperature range, and humidity exceeds $95 \%$. Table 2 presents correlations between surface air temperatures and airflow temperatures at points on the air intake route. These values are significantly higher than those at the various points on the return airflow route.

\subsection{Effect of surface air temperature variation on underground airflow temperature}

\subsubsection{Influence of surface temperature on underground temperature}

A 48-h temperature observation was conducted at the pithead and MPs. The results are presented in Fig. 5. The correlations between the wellhead temperatures and intake air temperatures at the shaft station and working face temperatures are presented in Table 3.

The air temperature on the surface reached the highest value at approximately 14:00, and the lowest at daybreak.

Table 3 Correlations between wellhead and intake air temperatures at the shaft station and working face

\begin{tabular}{llll}
\hline Date & Location & Correlation coefficient & Correlation \\
\hline August 02, 2013 & The surface-shaft station & 0.854 & Correlated \\
& The surface-The entrance of 2302S work face & 0.235 & Uncorrelated \\
August 03, 2013 & The surface-shaft station & 0.968 & Correlated \\
& The surface-The entrance of 2302S work face & 0.085 & Uncorrelated \\
\hline
\end{tabular}



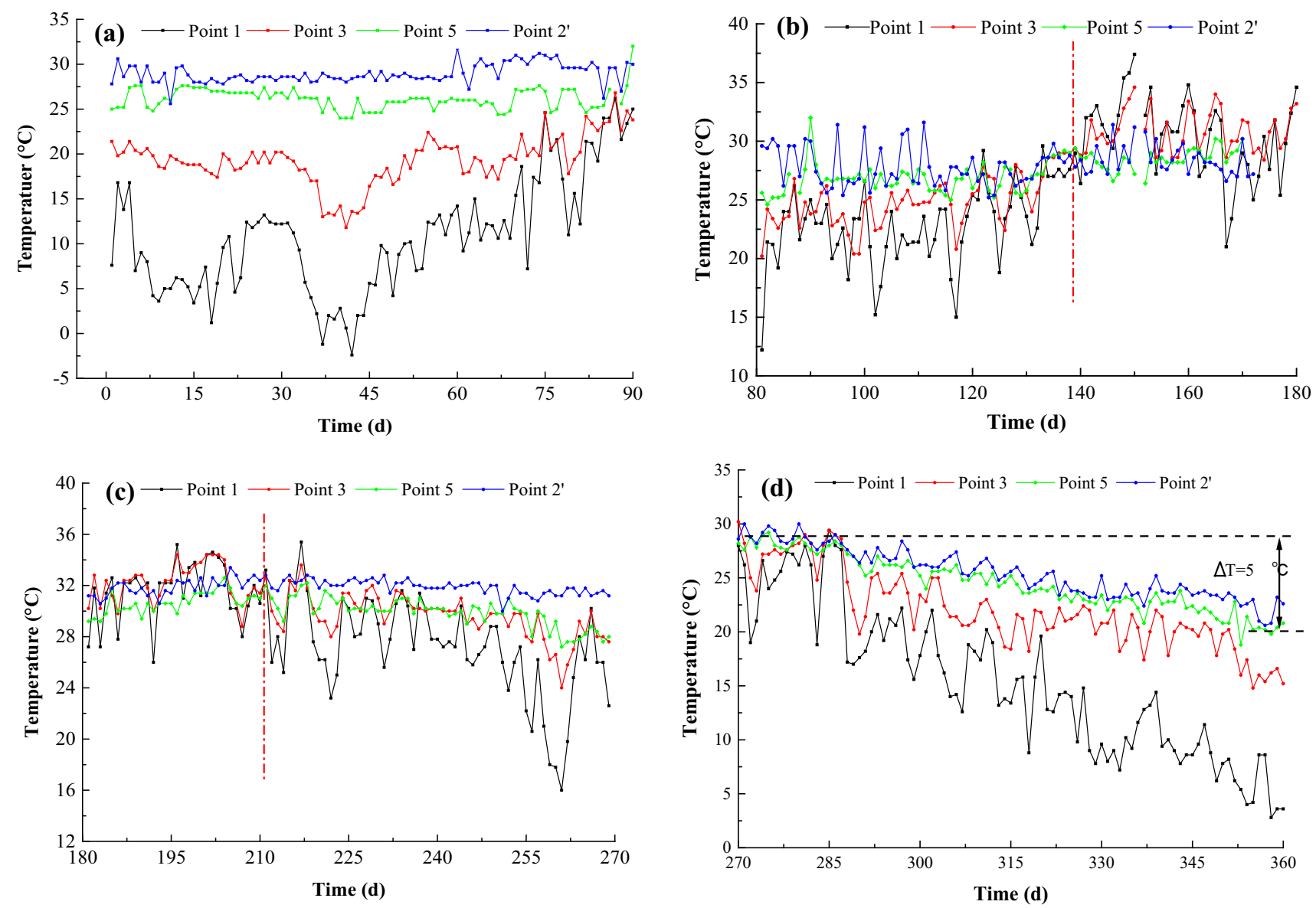

Fig. 6 Effect of surface climate on underground climate in different seasons for the $2302 \mathrm{~S}$ working face during a the first quarter, $\mathbf{b}$ second quarter, $\mathbf{c}$ third quarter and $\mathbf{d}$ the fourth quarter

As shown in Fig. 5, the change in air temperature in the shaft stations resembles that at surface and the range of variation is significantly attenuated. When the airflow passes through the mine shaft, heat is exchanged with the surrounding rock, leading to adverse temperature changes in the shaft stations. The air then passes along the roadway from the shaft station to the working face, and the heat and humidity exchange between the air and surrounding rock significantly reduces the influence of surface air temperature on the air temperature. Therefore, the correlation coefficient between the surface air temperature and airflow temperature of the intake entry at the working face is reduced. The same is evident for the correlation coefficient between the surface air temperature and the airflow temperature of the shaft stations.

\subsubsection{Influence of seasonal temperature variation on underground temperatures}

Figure 6 presents graphs illustrating the changes in surface and underground temperatures during different seasons.
Table 4 lists the calculated correlation results between underground and surface air temperatures.

As shown in Fig. 6a, the surface air temperature was low during the first quarter of the year. The airflow temperature first decreased and then increased in the airflow inlet route. The surface air temperature increased over time (Fig. 6b), whereas the difference decreased in the second quarter. During mid-May the surface air temperature exceeded the underground air temperature, most likely because the surrounding rock absorbed heat from the air, thus reducing the underground air temperature. Figure $6 \mathrm{c}$ indicates that the surface air temperature was still higher than the underground air temperature in July. The surface air temperature gradually decreased and was lower than the underground temperature in mid-August. The surface air temperature continued to decrease over time (Fig. 6d), and the difference between the surface and underground temperatures increased gradually in the fourth quarter. Thus, it is evident that surface air temperature exerts a significant influence over airflow temperature in the underground inlet section. This effect appears to decrease with increasing 
Table 4 Correlations between surface temperature changes at the wellhead and underground measuring points

\begin{tabular}{|c|c|c|c|}
\hline Quarter & Location & Correlation coefficient & Correlation \\
\hline \multirow[t]{8}{*}{ First quarter } & $1-2$ & 0.834 & Correlated \\
\hline & $1-4$ & 0.702 & Correlated \\
\hline & $1-5$ & 0.224 & Uncorrelated \\
\hline & $1-7$ & -0.050 & Uncorrelated \\
\hline & $1-1^{\prime}$ & 0.016 & Uncorrelated \\
\hline & $1-2^{\prime}$ & 0.428 & Correlated \\
\hline & $1-3^{\prime}$ & 0.229 & Uncorrelated \\
\hline & $1-4^{\prime}$ & 0.257 & Uncorrelated \\
\hline \multirow[t]{8}{*}{ Second quarter } & $1-2$ & 0.832 & Correlated \\
\hline & $1-4$ & 0.750 & Correlated \\
\hline & $1-5$ & 0.449 & Correlated \\
\hline & $1-7$ & -0.387 & Uncorrelated \\
\hline & $1-1^{\prime}$ & 0.391 & Correlated \\
\hline & $1-2^{\prime}$ & 0.273 & Uncorrelated \\
\hline & $1-3^{\prime}$ & 0.294 & Uncorrelated \\
\hline & $1-4^{\prime}$ & 0.509 & Correlated \\
\hline \multirow[t]{5}{*}{ Third quarter } & $1-2$ & 0.924 & Correlated \\
\hline & $1-4$ & 0.850 & Correlated \\
\hline & $1-5$ & 0.609 & Correlated \\
\hline & $1-1^{\prime}$ & 0.197 & Uncorrelated \\
\hline & $1-4^{\prime}$ & 0.291 & Uncorrelated \\
\hline \multirow[t]{7}{*}{ Fourth quarter } & $1-2$ & 0.905 & Correlated \\
\hline & $1-4$ & 0.907 & Correlated \\
\hline & $1-5$ & 0.899 & Correlated \\
\hline & $1-6$ & 0.895 & Correlated \\
\hline & $1-7$ & 0.894 & Uncorrelated \\
\hline & $1-1^{\prime}$ & -0.234 & Uncorrelated \\
\hline & $1-2^{\prime}$ & -0.785 & Uncorrelated \\
\hline
\end{tabular}

length of the ventilation route. In winter, the surrounding rock has a heating effect on airflow, but in the second quarter, the surrounding rock has a cooling effect.

\subsubsection{Temperature variation at the working face}

(1) Temperature variation regularity at the working face

We selected four time-temperature curves from a typical production day in the mine. In a typical day the production time is from 14:30 to 08:30, with maintenance from 08:30 to $14: 30$. As shown in Fig. 7, the airflow temperature variation from the inlet to the return airflow route first decreases and then increases. The measuring points of the airflow temperature are shown in Fig. 3.

The airflow temperature curve can be divided into four stages. Before reaching the cooling apparatus of the inlet roadway, the airflow temperature decreases moderately, decreasing by approximately $1.2^{\circ} \mathrm{C}$. After passing through a two-stage air cooler, the temperature drops significantly. The first cooling was recorded by a temperature reduction of $4.7^{\circ} \mathrm{C}$, and the second cooling by a further $2.3{ }^{\circ} \mathrm{C}$ reduction. The minimum temperature of approximately $25.0{ }^{\circ} \mathrm{C}$ was reached before encountering the working face inlet. The airflow temperature transitioned to the fourth stage after entering the working face, and the temperature increased gradually by $8.0{ }^{\circ} \mathrm{C}$ to reach a maximum of $32.59{ }^{\circ} \mathrm{C}$ as airflow proceeded to the dissipation outlet of the working face. The airflow temperature was lower than normal during maintenance of the working face. Residual temperature readings mainly resulted from heat dissipation from the surrounding rock, electrical devices, and the hightemperature airflow of the goaf. Electrical devices were not

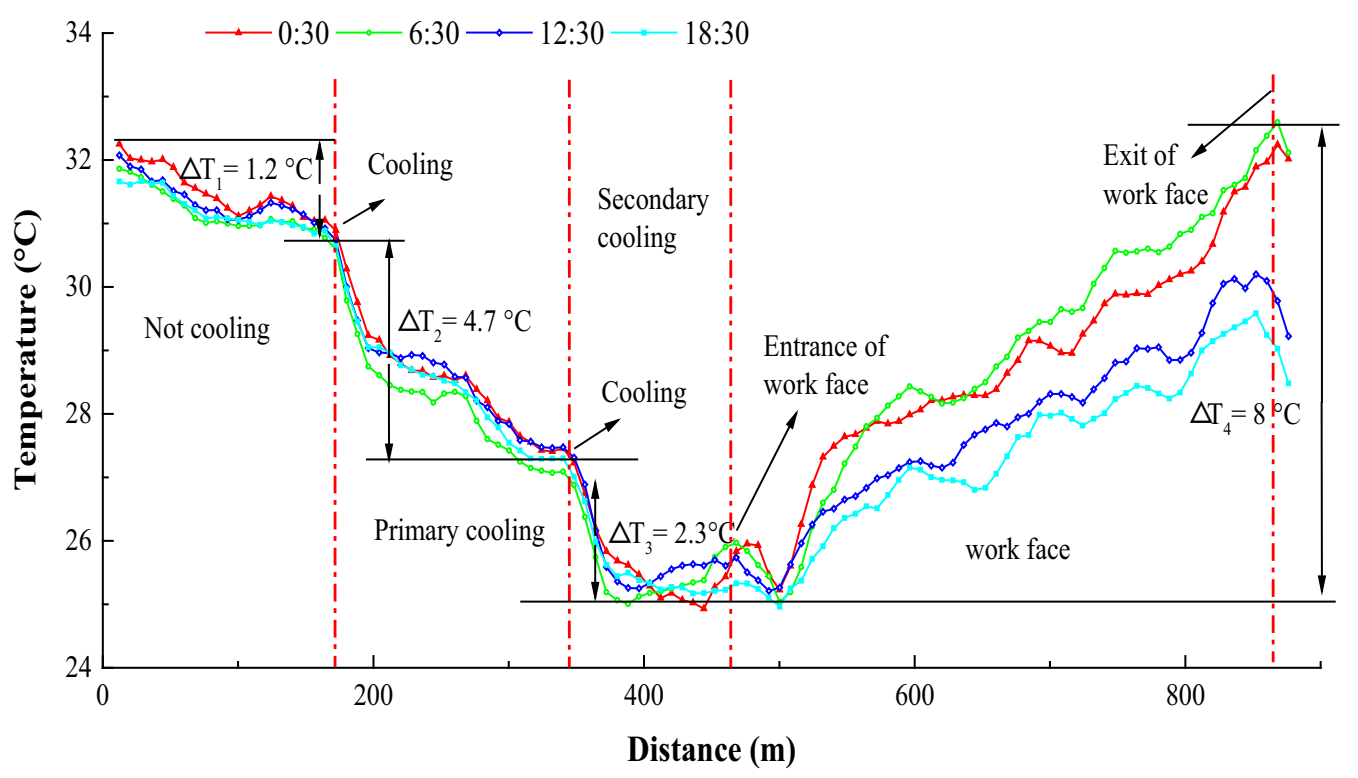

Fig. 7 Daily temperature variation at the working face 
in operation at the working face during maintenance, resulting in reduced heat output and a reduction in heating of the air.

(2) Airflow temperature variation at the working face MPs

The average temperatures at different locations at the working face were analyzed over the period of four seasons (Fig. 8 and Table 4). Airflow temperature was measured from the start of the upper working face to the lower working face. In Fig. 8, the upper working face is designated as $0 \mathrm{~m}$, and the lower working face is at $270 \mathrm{~m}$. The direction of the airflow temperature measurement was consistent with the direction of the airflow at the working face, which was the direction of the airflow from 0 to $270 \mathrm{~m}$. The airflow traveled from the entrance of the working face to the local underground cooling system, and
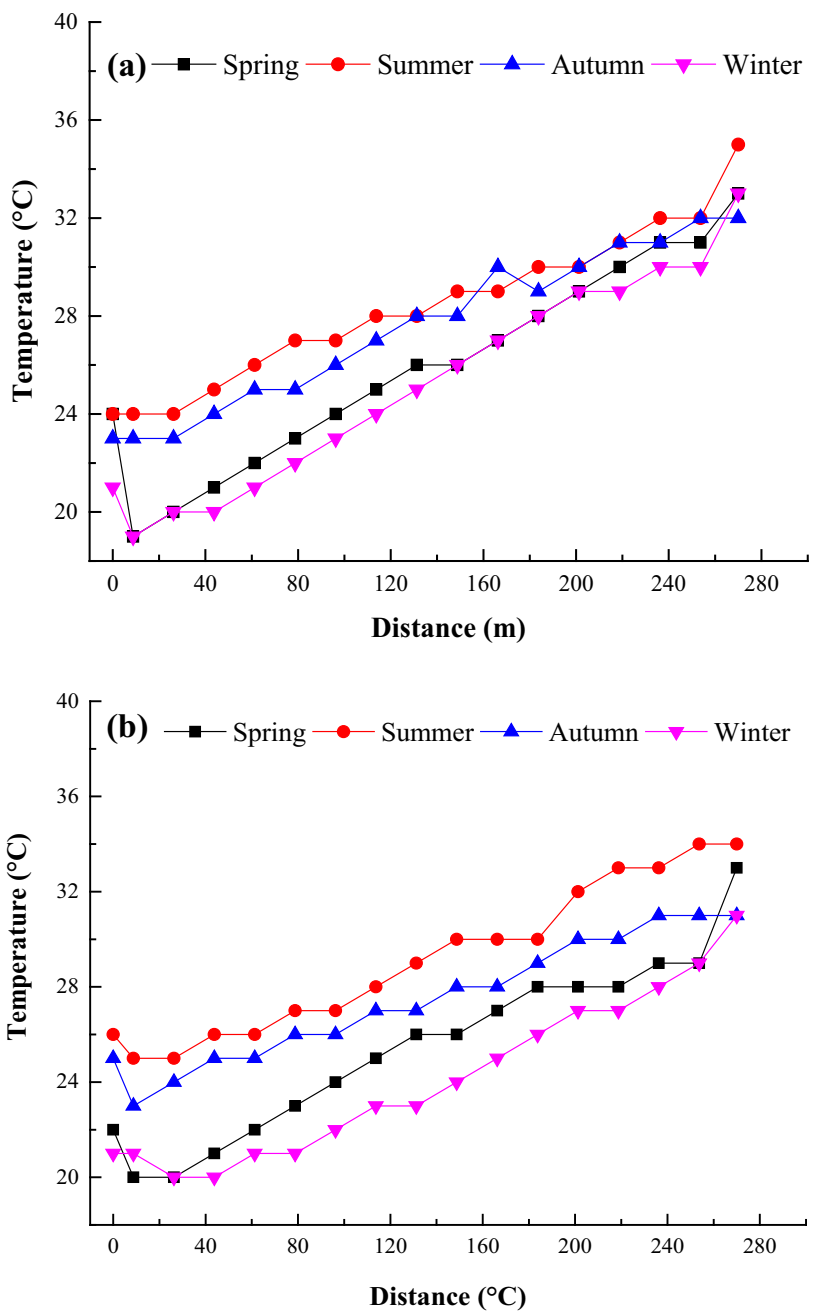

Fig. 8 Airflow temperature curves at different positions of the 2302S working face. a During maintenance, $\mathbf{b}$ during production. Note that the upper working face is designated as $0 \mathrm{~m}$, and the lower working face is at $270 \mathrm{~m}$ the temperature dropped significantly $\left(22-24{ }^{\circ} \mathrm{C}\right)$. As the area of most concentrated heat dissipation, the working face has considerably higher dissipation than both sides of the transport area and track. Also, the primary heat source at the working face is heat dissipation from electrical equipment. The increasing surface air temperature aggravated thermal pollution, leading to higher temperatures in summer. The temperature difference between summer and the other seasons is in the $1.0-3.0^{\circ} \mathrm{C}$ range.

\subsection{The temperature field of surrounding rocks}

The results obtained from monitoring of surrounding rock temperatures for 4 to 5 consecutive days are presented in Fig. 9.

It is clear from Fig. 9 that the surrounding rock temperatures increase with increasing borehole depth. Before reaching its maximum, the temperature in the rock constantly increases with increasing depth. However, the rate first increases and then decreases, and then ultimately stabilizes. The surface layer of the surrounding rock cracked because of mining, and the flow of air through the crack accelerated heat dissipation from the surrounding rock. Therefore, the shallow rock formation in the boreholes had limited thermal resistance and low heating rates. When the depth of the borehole exceeded the fissure zone in the surrounding rock, the influence of tight airflow in the strata became significantly reduced, causing a significant increase in thermal resistance and a related sudden increase in temperature. The temperature difference between the surrounding rock and the original rock decreased continuously with increasing temperature after the fracture zone. Therefore, the temperature of the original rock decreases with increasing depth.

When the drilling depth of Coal Seam 1 reached $32.75 \mathrm{~m}$, the surrounding rock temperature reached a maximum value of $39.83{ }^{\circ} \mathrm{C}$. Before reaching this value, the rate gradually decreased by $1.7{ }^{\circ} \mathrm{C}$, because the end of Coal Seam 1 is only $26.4 \mathrm{~m}$ away from the north return airflow route and extends into the heat-adjusting layer of the north airflow route. After the depth of Coal Seam 2 reached $28.5 \mathrm{~m}$, the temperature reached $40.3{ }^{\circ} \mathrm{C}$ and tended towards a steady state. The temperature of the surrounding rock for Coal Seam 3 increased to a steady state, reaching a maximum temperature of $40.3{ }^{\circ} \mathrm{C}$. By analyzing the surrounding rock of the roadway at the MP, it is evident that the temperature of the surrounding rock increases with a change in the distance between the wall and roadway. Moreover, the gap in isotherms is more evident, and the temperature stabilizes after the rock temperature exceeds $40.5^{\circ} \mathrm{C}$. The radius of the heat-adjusting layer is equal to the sum of the thickness before temperature stabilization and equivalent radius of the roadway. 

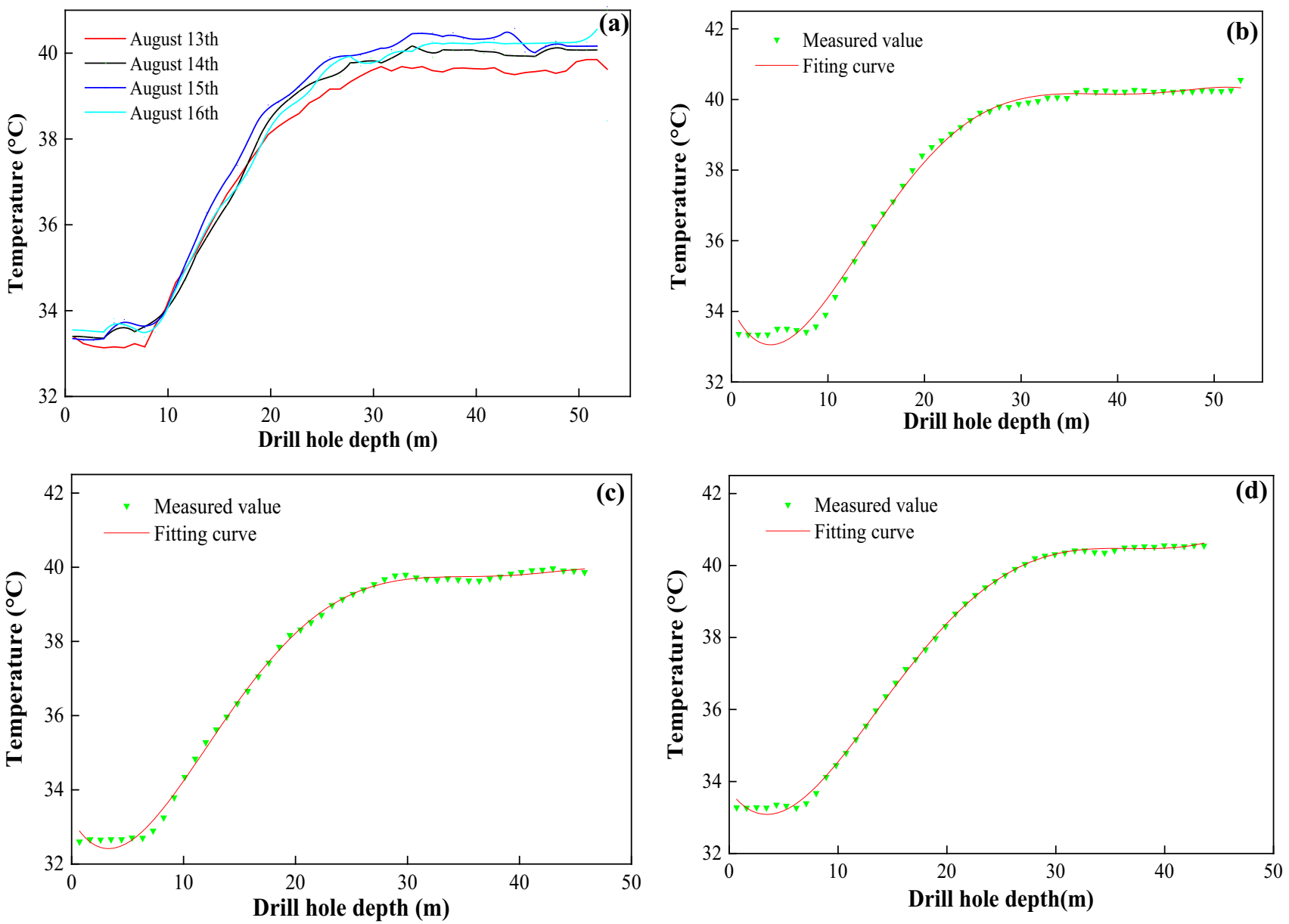

Fig. 9 Correlation curves of hole depth versus surrounding rock temperatures measured in boreholes: a measuring point at Coal Seam 1, b temperature and fitting curve of Coal Seam 1, c temperature and fitting curve of Coal Seam 2 and $\mathbf{d}$ temperature and fitting curve of Coal Seam

Therefore, the radius of the heat-adjusting layer of the surrounding rock is between 28 and $33 \mathrm{~m}$.

\section{Conclusions}

This study investigated the effects of seasonal variation in surface air temperatures on mine airflow temperatures. The main findings are:

(1) In the inlet section of the mine, airflow temperature is significantly influenced by seasonal variations in air temperature near the surface. The further the air inlet is from the wellheads, the lower the impact. However, surface air temperature has little effect on airflow temperature on the return route.

(2) The airflow temperature variation of the ventilation circuit first decreases, then increases. The maximum recorded airflow temperature of the outlet under the working face was $32.59^{\circ} \mathrm{C}$; an increase of $8.0^{\circ} \mathrm{C}$.
(3) The temperature of the field distribution of the surrounding rock gradually increases with increasing distance of the inlet from the roadway surface. The highest temperature recorded was $40.53{ }^{\circ} \mathrm{C}$. Moreover, the radius of the heat-adjusting layer is between 28 and $33 \mathrm{~m}$.

Acknowledgements This work was supported by the National Natural Science Foundation of China (Nos. 5157-4139 and 5180-4247), De Montfort University through its distinguished Vice-Chancellor 2020 Programme, and UK Science and Technology Facilities Council (STFC) through Batteries Early Career Researcher Award.

\section{Compliance with ethical standards}

Conflict of interest The authors declare that they have no conflict of interest.

Open Access This article is distributed under the terms of the Creative Commons Attribution 4.0 International License (http://crea tivecommons.org/licenses/by/4.0/), which permits unrestricted use, distribution, and reproduction in any medium, provided you give appropriate credit to the original author(s) and the source, provide a 
link to the Creative Commons license, and indicate if changes were made.

\section{References}

Apel D, Liu W, Bindiganavile V (2014) Simulation of the effects of thermal insulating shotcrete on the energy consumption of ventilation and cooling systems at deep underground mines. Mine planning and equipment selection. Springer, Berlin, pp 37-42

Castillo D, Burn A, Pieters A, Volk B (2003) The design and implementation of a $17 \mathrm{MW}$ thermal storage cooling system on a South African mine. International Congress of Refrigeration, Washington, pp 1-8

Chen W, Liang S, Liu J (2016) Proposed split-type vapor compression refrigerator for heat hazard control in deep mines. Appl Therm Eng 105:425-435

Chu Z (2015) Analysis and application of mine air heat-sink capacity in deep mine heat hazard control. J Mines Met Fuels 63:141-146

Danko G, Bahrami D (2008) Application of multiflux for air, heat and moisture flow simulations. In: 12th U.S. North American mine ventilation symposium 2008. Nevada, USA, Nevada University Press, pp 267-274

Deng J, Wang K, Zhang Y, Yang H (2014) Study on the kinetics and reactivity at the ignition temperature of Jurassic coal in north Shaanxi. J Therm Anal Calorim 118:417-423

Guo P, He M, Zheng L, Zhang N (2017) A geothermal recycling system for cooling and heating in deep mines. Appl Therm Eng 116:833-839

Hargreaves DM, Lowndes IS (2007) The computational modeling of the ventilation flows within a rapid development drivage. Tunn Undergr Sp Technol 22:150-160

He M, Guo P (2013) Deep rock mass thermodynamic effect and temperature control measures. Chin J Rock Mechan Eng 12:2377-2393

He M, Cao X, Xie Q, Yang J, Qi P, Yang Q, Chen X (2010) Principles and technology for stepwise utilization of resources for mitigating deep mine heat hazards. Int J Min Sci Technol 20:20-27

Heerden CV (1951) A problem of unsteady heat flow in connection with the cooling of collieries. In: Proceedings of the general discussion on heat flow. Institute Mechanical Engineering, pp. $283-285$

Kamyar A, Aminossadati SM, Leonardi C, Sasmito A (2016) Current developments and challenges of underground mine ventilation and cooling methods. In: 2016 Coal operators conference. The
University of Wollongong Printery, New South Wales, AUS, pp 137-154

Lowndes IS, Pickering SJ, Twort CT (2004a) The application of energy analysis to the cooling of a deep UK colliery. J S Afr Inst Min Metall 08:381-396

Lowndes S, Crossley AJ, Yang Z (2004b) The ventilation and climate modelling of rapid development tunnel drivages. Tunn Undergr Sp Technol 19:139-150

Ngô V, Nadeau S, Hallé S (2017) Ergonomic design of a cooling vest in deep and ultra-deep mining environments. Occup Ergon 13:115-126

Nie X, Wei X, Li X, Lu C (2018) Heat treatment and ventilation optimization in a deep mine. Adv Civ Eng 2018:1-12

Onder M, Sarac S, Cevik E (2006) The influence of ventilation variables on the volume rate of airflow delivered to the face of long drivages. Tunn Undergr Sp Technol 21:568-574

Pherson MJ (2012) Subground ventilation and environmental engineering. Springer, Berlin

Raghavendra R, Vinod Y (2009) Multi-objective optimization of Nd: YAG laser cutting of thin superalloy sheet using grey relational analysis with entroy measurement. Opt Laser Technol 41:922-930

Su Z, Jiang Z, Sun Z (2009) Study on the heat hazard of deep exploitation in high-temperature mines and its evaluation index. Procedia Earth Planet Sci 01:414-419

Wang M, Liu L, Chen L, Zhang X, Zhang B, Ji C (2018) Cold load and storage functional backfill for cooling deep mine. Adv Civ Eng 2018:1-8

Xie Z (2012) Distribution law of high temperature mine's thermal environment parameters and study of heat damage's causes. Procedia Eng 43:588-593

Xie H, Zhou H, Xue D, Wang H, Zhang R, Gao F (2012) Research and consideration on deep coal mining and critical mining depth. J China Coal Soc 04:535-542

Yakovenko K, Averin GV (1984) Determination of the heat-transfer coefficient for a rock mass with small fourier numbers. J Min Sci 20:52-56

Yang X, Han Q, Pang J, Shi X, Hou D, Liu C (2011) Progress of heathazard treatment in deep mines. Int $\mathrm{J}$ Min Sci Technol 21:295-299

Zhang X, Yu W, Wang C (2006) Three-dimensional nonlinear analysis of coupled problem of heat transfer in the surrounding rock and heat convection between the air and the surrounding rock in the Fenghuo mountain tunnel. Cold Reg Sci Technol $44: 38-51$ 